\title{
Legislation and drug safety
}

\author{
PROFESSOR SIR ERIC SCOWEN
}

The control of medicines by the Medicines Act of 1968 was designed for the protection of the individual patient and of the community from harmful effects and indiscriminate uses of medicines. The Act was, in the main, a work of synthesis, of putting together various facets of previous legislation, rather than exploration or originality. Yet it could, perhaps, claim the mixture of attempting to impose some order on the many pieces of a jigsaw, of drawing scattered threads together and sewing them into a more intelligible pattern than the piecemeal arrangements developed over the last two hundred years.

The evaluation of the control of medicines in drugs has a special interest, for it clearly shows the innate unwillingness to provide for governmental control until the demand of the general population, from a philanthropic or emotional drive, galvanizes statutory action.

The first essay into the control of drugs arose in the eighteenth century, when the introduction of gin into this country offered solace to the poor from the anxieties of poverty, disease and overcrowding. The persistent drunkenness led to further decay of social conditions but little happened to control this until the conscience of many was stirred by the direct and indirect effects on children. During this time in London the death rate in children under 5 years of age greatly exceeded the baptism rate. The public outcry demanded action and this was enhanced by the works of Hogarth, which so vividly depicted the horrors of the situation. This point needs emphasis for it demonstrates the power of emotive rather than objective reason to the urge that 'they', ie, the Government, must do something about it. This theme recurrs throughout the various stages of legislative evolution in this context.

There followed during the eighteenth century the various Gin Acts which sought primarily to control the sale and supply of this drug. The early efforts were thwarted by the manufacturers and the farmers supplying the grain, for it was useless to prosecute the impecunious proprietor of a gin shop when others could open premises next day. The matter was finally solved by taxation, which placed gin outside the financial range of the majority, but at the same time provided that porter and similar beverages were made cheaper and were easily obtainable. Nevertheless, there were unfortunate lapses and more people died from gin during the Gordon Riots when some distilleries were ransacked than from the fighting which ensued before the riots were quelled.

From this time on for the best part of a century, there was little attempt to control medicines, although the development of the pharmacopoeias by the Royal Colleges began to regulate the formulation and contents of medicines.

In the middle of the nineteenth century the widespread use of arsenic resulted in the passing of the Arsenic Act of 1851 which sought to control the outlet for the sale of the preparation of arsenic available. It provided for a list of approved sellers and a register had to be kept of each sale and the purchaser was required to sign the register. It is of interest that many signatures were missing and illustrates the widespread illiteracy, so that a mark or thumb print had to suffice. This exercise seems largely to have been undertaken to control criminal activities and to prevent the excessive use of 'inheritance powders'. I think this name is self explanatory, but underlines the reason for the control and identification of the purchaser.

In 1964 the first British Pharmacopoeia was published, which set the standards for the control of the quality of medicines. Through progressive editions this book has continued and has come a long way in setting high standards to ensure the purity and potency of medicines. The British Pharmacopoeia has rightly enjoyed an international reputation and it is a little ironic to think that, until the Medicines Act 1968 , it had no statutory standing, though it says a great deal for legal common sense that it has always been accepted as the presumptive standard for quality in cases of controversy.

The Pharmacy Act of 1868 brought about the control of the sales of poisons. The initial substances named have some interest, for it is clear that it sought to remedy a number of abuses which were prevalent : as examples, opium and its preparations, which had endeared themselves to the ladies of the late Georgian and early Victorian eras, especially in the form of laudanum. Oil of savin was in this list, probably not efficacious, but highly thought of as an abortifacient. Cantharides was also listed and not, I think, because of its blistering properties. This Act vested in the Pharmaceutical Society of Great Britain the right to suggest new poisons which should be added to this list. Poison was, therefore, more a humpty-dumpty word and meant what the Society 
meant it to say. Nevertheless, a useful purpose was achieved by limiting the sale and supply to certain responsible outlets.

At the end of the second decade of the twentieth century, the Government began to realize that it had handed over to an extra-government agency the control of poisons and there followed the enactment of the first Pharmacy and Poisons Act which established, amongst other things, that the responsibility to provide for the control and sale and supply of poisons should be vested in the Home Office and a statutory Poisons Board be set up to advise on the substances to be controlled and what controls should be applied. This was essentially an extension of the control of sale and supply.

Schedules to the Poisons List were gradually added so that progressive restrictions were applied for controlling supply by limitation to pharmacies by prescription and by labelling and container requirements.

The original designs of the Act were gradually obscured by the increasing use of the lists to include medicines since this was the only route available easily to restrict the supplies to outlets from pharmacies and by medical prescription. For many years the system worked but became progressively more difficult to contain as the major part of the Poisons List had become medicines. This added to the necessity to clarify the legislation on medicines and to the elaboration of a new Poisons Act which is specifically concerned with non-medicinal poisons. But the principles of control by prescription, by pharmacy sale and by controlling containers and labelling had been tested and accepted.

The Dangerous Drug Acts began the full control of narcotics and for the first time controlled not only sale and supply but also manufacture and distribution. It enlarged the necessities of sales registers, but also introduced the licensing of manufacture both to premises and to quantity. These Acts were limited in their application and were not suitable for the modern drug explosion. It became necessary to extend control under the Misuse of Drugs Act so that a wide category could be controlled, but fortunately allows control of the substances, unlike the Medicines Act, which controls medicinal products, with few exceptions such as antimicrobial substances.

The promotion of nostrums and cures for cancer and venereal disease preyed on the gullibility of the public. The Government recognized the necessity to control such advertisement to prevent such deception which could prove a social evil in the case of venereal disease, and a more insidious but malignant influence in the treatment of cancer.

With the advent of biological and immunological products, further control became necessary. These products could not readily be controlled by reference to a pharmacopoeial monograph and required special care both in the process of manufacture and in the assessment of the final product. The Therapeutic Substances Act introduced the idea of in-process control and supervision as well as the application of biological assay for substances, of which the purity and potency cannot be ascertained by chemical means. This Act also introduced a further new concept that substances might be restricted to prescription by authorized practitioners if the indiscriminate use of them might be a hazard to the community.

Within this bewildering complex of legislation, certain concepts had emerged. The control of quality, the control of sale and supply and, in some cases, the licensing of manufacture had been recognized. The necessity for controlling the use by prescription to protect both patient and community had been accepted. The control of advertisement had been introduced. The supervision of manufacture and the approval for marketing biological products was limited, however, to a few products only.

Such was the scene for the entry of the present therapeutic explosion. The overture sounded in the United States of America with disaster from a sulphonamide elixir and the deaths which followed the use of an excipient which blocked the kidneys with its oxalate metabolites. There followed the drama of the thalidomide disaster.

Lulled by years of quietude, the existing legislationce was clearly unprepared for modern conditions. The? public emotion demanded action. A large gap had been shown in the defences which had been built over many years. Apart from the biological products under the control of the Therapeutic Substances Act, anyone could market any product, however dangerous or inadequately tested, without any official approval. The Ministers of Health therefore established the Safety of Drugs Committee in 1963 as an interim measure until more comprehensive legislation could be enacted and appropriate regulations written. It was a voluntary arrangement between Committee and industry. The members were appointed by the Health Ministers, but the Committee was solely responsible for its decisions. The pharmaceutical industry agreed that, after the Committee started to function in January 1964, none of its members would put a new product to clinical trial and no new product would be marketed without the advice of the Committee. The manufacturers were glad to share the responsibility for the safety of their products with an independent body, whose major remit concerned safety. The Committee did not approve any substance as a therapeutic agent, but raised no objection to its trial or marketing if it was satisfied of its reasonable safety for the intended use. 
Admittedly safety and efficacy are inextricably mixed, but efficacy alone was not the function of the Committee.

The Safety of Drugs Committee undertook this work with the help of three subcommittees: the first to scrutinize the studies undertaken before clinical trials; the second to study the adequacy of clinical trials before marketing; the third to set up a system for monitoring adverse reactions after marketing. This last information was obtained by voluntary notification from practitioners and from the pharmaceutical industry and enabled the Committee to monitor not only new drugs but drugs which were previously marketed and to feed the information back to the professions.

Contact with industry was free and informal and permitted an easy exchange of information. The Committee could make its own case law and thus maintained a flexible attitude untrammelled by statutory rigidity.

There remained a need to provide a system to ensure that the best conditions for the manufacture, storage and distribution of medicines should obtain. In addition there was a relatively ineffective machinery to enforce the quality control of preparations, whether manufactured in this country or imported. There was no mechanism for controlling the standards of promotion or advertisement.

The Medicines Act passed through Parliament in 1968 and became operative in 1971. The Act provided for the control of both human and veterinary medicines as well as medicated animal feeding stuffs. It also enabled control to be exerted on a wide range of materials used in medicine.

The Secretary of State for Health and Social Security, the appropriate health ministers, and the Minister of Agriculture are required to act as a licensing authority to issue certificates for clinical trial and licences for the marketing, importation and manufacture of medicines for human and veterinary use. This licensing authority is advised by a statutory Committee on Safety of Medicines, having regard to the safety, equality and efficacy of medicinal products. Financial considerations are not within their remit nor is relative efficacy except in relation to safety.

The Committee on Safety of Medicines studied carefully the experience of the Committee on Safety of Drugs and maintained many of its features in a subcommittee structure. It therefore arranged a number of subcommittees to help it to undertake its responsibilities. Separate expert subcommittees advise on toxicity and clinical trials, on pharmacy and chemistry, on biological products and on adverse reactions, both in collection and interpretation. It has also developed a Joint Sub-Committee with the
Veterinary Products Committee to advise on all matters relating to the introduction and use of antimicrobials, both to minimize inappropriate and indiscriminate use and to safeguard the community from the undesirable effects which could occur both in the environment and in the food cycle.

The Committee is well aware of the many unsolved problems with which it is faced. It is constantly reviewing its procedures for it well understands that, when complex solutions for the handling of complex problems have been long in the making, their solution may no longer be appropriate.

The precise definition of 'safety' and of 'efficacy' has never been attained. Assessments are, therefore, inevitably a question of judgment, which can only be exercised on available knowledge. There is the strong necessity for continual and continuous experiment and innovation in methods and the methodology of assessment if improvement is to continue, so that the level of predictive evaluation shall progressively improve.

The Committee is eternally vigilant to prevent an elaborate system taking on an elegance of its own. Such a system can become, as has been said elsewhere, a massive dust catcher, never capable of being tidied up. As a bureaucratic phenomenon, a preoccupation with details tends to become an end in itself, as with much of the masses of data which bureaucracies of all kinds continue to accumulate without apparent use, the original purposes long forgotten or passed into desuetude.

By constant self examination, the Committee hopes to approach the ideal system of advice to the licensing authority, which has been defined with the following requirements: (1) it should safeguard the individual patient from harm inflicted by old medicines and the testing of new ones; (2) it should seek to ensure that only drugs with proven efficacy should be marketed and ensure the quality and constancy of such products; (3) it should ascertain that there is an acceptable ratio between possible adverse reactions and therapeutic benefits; (4) it should provide a choice of similarly acting drugs to enable the physician to satisfy the varying needs of the biological variations of his patients; (5) it must take care not to stifle creativity and innovation in drug research, nor burden industry and hence the public with unnecessary expenditure for data which are of little value; (6) it must protect the community from the indiscriminate use of medicines, which could render nugatory their eventual therapeutic efficacy; (7) it must protect the community from the dangers which may occur through the food cycle from the use of medicinal substances in horticulture, agriculture and veterinary medicine particularly in relation to antimicrobials. 